$\mathbb{P}$ Periodica Polytechnica Transportation Engineering

45(3), pp. 141-147, 2017

https://doi.org10.3311/PPtr. 10607

Creative Commons Attribution (i)

RESEARCH ARTICLE

\section{Effect of Operating Point Selection on Non-linear Experimental Identification of iSTC-21v and TKT-1 Small Turbojet Engines}

\author{
Ladislav Főzö ${ }^{1 *}$, Rudolf Andoga ${ }^{2}$, Károly Beneda ${ }^{3}$, Jan Kolesár ${ }^{4}$ \\ Received 07 November 2016; accepted 03 February 2017
}

\begin{abstract}
Precise dynamic mathematical models of complex systems are important in control and diagnostic systems design and allow testing a complex system in virtual environment at a low cost. They can be also utilized in rapid prototyping using a concept of hardware in the loop. Ever improving methods of experimental identification and using approaches in non-linear approximation can considerably increase the precision of dynamic models of complex systems. The article deals with non-linear approximation of transfer gains of a complex system and evaluates the influence of operational point selection on precision of the resulting model using methods of experimental data driven identification. The object of control is represented by two similar small turbojet engines at the Departments of the authors, the iSTC-21v and TKT-1, both based on the same power section having two degrees of freedom: fuel mass flow rate and variable convergent nozzle position.
\end{abstract}

\section{Keywords}

turbojet engine, gas turbine, experimental identification, dynamic mathematical model, operational point, non-linear system, variable exhaust nozzle, MATLAB Simulink

\footnotetext{
${ }^{1}$ Department of Aviation Engineering, Faculty of Aeronautics, Technical University of Košice, 04121 Košice, Rampová 7, Slovakia

${ }^{2}$ Department of Avionics, Faculty of Aeronautics, Technical University of Košice, 04121 Košice, Rampová 7, Slovakia

${ }^{3}$ Department of Aeronautics, Naval Architecture and Railway Vehicles, Faculty of Transport Engineering, Budapest University of Technology and Economics, H-1521 Budapest, P.O.B. 91, Hungary

${ }^{4}$ Department of Air Transport Management, Faculty of Aeronautics, Technical University of Košice, 04121 Košice, Rampová 7, Slovakia

Ladislav Föző Researcher ID: H-5018-2016

Rudolf Andoga Researcher ID: H-5026-2016

Károly Beneda Researcher ID: H-4946-2016

Jan Kolesár Researcher ID: H-8576-2016

"Corresponding author, e-mail: ladislav.fozo@tuke.sk
}

\section{Introduction}

Novel approaches for aviation are probably more demanding nowadays than ever before, the future efficient and sustainable air transport needs new, even radically new solutions (Rohács D. and Rohács J., 2016; Truman and Graaff, 2006; 2007). During research team activity in our laboratories we must solve very complex task, which demands a specially designed very precise dynamic model of the engine suitable for solution of this task according to Jaw and Mattingly (2009). There are many approaches, which can be taken in design of a dynamic model of a complex non-linear system in general as well as specialized methodologies for creation of dynamic models of turbo-compressor engines as reported by Kulikov and Thompson (2004).

Andoga et al. (2013), highlighted in their work that a dynamic model, which can be very precise in a diagnostic system and can be used to successfully compute virtual parameters of the engine in real-time does not necessarily have to be suitable for control system design. Such models were e.g. designed in Adamčík et al. (2014), however these models failed in control system design as algorithms created using them didn't work on the real-world objects of small turbojet engine iSTC-21v and TKT-1.

A small turbojet engine is a complex non-linear system with non-stationary characteristics and is representative of many other like-wise complex real-world systems as described in Zare and Veress (2013) or Bicsák and Veress (2015). One of the non-stationary characteristics of such engine is the gain of the transfer function of the engine, which can be sometimes handled with linear control approaches, as reported by Beneda (2015). But one has to understand that the gain of the transfer function is a non-linear function of many different parameters, like speed of the engine, velocity of the aircraft, airflow, temperature, pressure, etc. One of the dominant parameters influencing this gain constant is the actual speed of the engine (Jirgl and Jalovecky (2015)).

The article is aimed at research of methods for non-linear approximation of this gain and evaluate the precision of the resulting models. This approach is different from the classical approach of using a set of linear perturbed models using the 
Taylor series method of dividing the full operating range. As found in Armstrong and Simon (2012) or Tóth-Laufer, Takács and Rudas (2015), the non-linear approximation of the gain should be more precise, can be better implemented in realtime systems and can also utilize more advanced methods of approximation like neural networks or fuzzy inference systems, improving precision and flexibility of the resulting model.

The other question that needs to be solved in this approach, is the selection of initial operational point as it has influence on the complexity of the polynomial approximation. We will consider two approaches here, zero initial operational point means that the engine and the corresponding model starts from its cold state and non-zero initial operational point will use different operational conditions starting from idle speed of the engine; this means the engine is already running hot.

In the present article the investigation is completed with the iSTC-21v, but the TKT-1 would have similar results due to their common power sections.

\section{Deviation model of iSTC-21v and TKT-1 created by experimental identification}

Several methods can be applied in creation of a mathematic model from experimental data using a transfer function of a system. The simplest possible approach in order to model a single spool turbojet engine is to use a first order transfer function described as shown by Noskievic (1999):

$$
F(s)=\frac{K}{T s+1}
$$

where:

$K-$ is the static gain coefficient of the system,

$T$ - time constant of the system.

Gain is set as a ratio of stable values of input and output as follows:

$$
K=\frac{y_{\infty}}{u_{\infty}}
$$

for the engine iSTC-21v:

- $n$-speed of the engine (the output parameter $-\mathrm{y}_{\infty}$ ),

- $Q_{p a l}$ - fuel flow supply (the input parameter $-\mathrm{u}_{\infty}$ ).

According to Noskievic (1999), the time constant T can be simply computed by a tangent line to the transfer characteristics at its beginning or from the value of $0.63 \cdot y_{\infty}$. Coefficient $T$ is treated as a constant for the needs of this paper. This paper will deal mainly with non-linear approximation of the gain constant of the first order engine model in different operational regimes of the engine.

To compute the gain coefficient $K$ as denoted in literature and the (2) is computed as a step response, which starts in the beginning of the coordinate system and ends in the stable regime of operation. The problem is that the particular system, the engines iSTC-21v or TKT-1 does not start at the beginning of the coordinate system but has to get to a stable idle regime of operation, see Fig. 1.

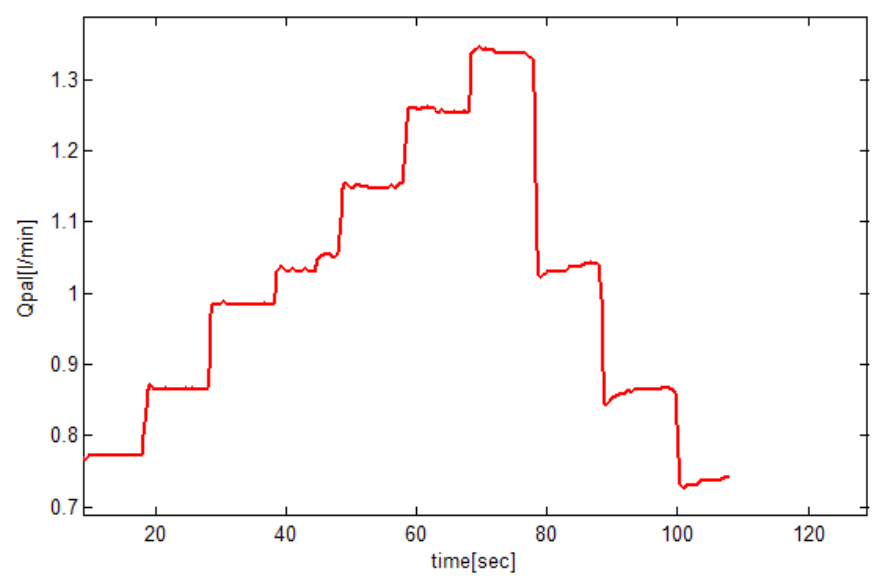

Fig. 1 Input signal - stable states of iSTC-21v engine

In order to build a model we can use several step signals from the stable fuel supply and because it is a non-linear system its static gain coefficient $K$ will be different in each operational point.

When the initial point does not origin from the beginning of a coordinate system a new formula for calculation of static gains can be defined as follows:

$$
K_{i, j}=\frac{y_{j, \infty}-y_{i, \infty}}{u_{j, \infty}-u_{i, \infty}}
$$

where

$i=0,1, \ldots, \mathrm{n}-$ is the chosen arbitrary stable operating point, it is usually idle or a regime higher than idle, which will be used to calculate differentiative $K$

$j=1,2, \ldots, \mathrm{m}-$ is the arbitrary chosen operational point for which the static gain will be computed, while $i \neq j$.

We choose one operating point " $i$ " and for all stable states we compute for actual (specifically) measurement " $j$ " gains $K_{i, j}$. We choose next operating point " $i$ " and for all stable states we again compute gains $K_{i, j}$. By that compute and by defining of gains $K$ which are computed by solving (3), we receive so named deviation non-linear system models, we will mark them $K_{i}$ ( $K_{i}$ model, given to $i$ operating point), for selected $i$ operating point. Deviation model because as (3) suggests, it's reduced by chosen, in almost all cases it is idle. In special case, which is not deviation and we can name it non-deviation non-linear system model $\left(K_{0}\right.$ model $)$ it is when we choose operating point " $i=0 "$ (coordinate system origin) and for all stable states we compute gains $K_{0, j}$, for which equation is:

$$
K_{0, j}=\frac{y_{j, \infty}-y_{0, \infty}}{u_{j, \infty}-u_{0, \infty}}=\frac{y_{j, \infty}-0}{u_{j, \infty}-0}=\frac{y_{j, \infty}}{u_{j, \infty}}
$$


From above we know in only one case if $j=1$, i.e. for one engine operating point and for $i=0$, i.e. coordinate system origin it is intended $K$ Eq. (2). If we compute them by that equation it will be fixed and we get non-deviation linear system model (in our case generally for aircraft engines or similar systems).

From above we learn to create deviation non-linear system models, i.e. $\Delta K_{i}$ models, where we compute deviation gain $\left(\Delta K_{i}, i=1,2, \ldots, \mathrm{n}\right)$ for various operating points related to various stable states or non-deviation non-linear system model, i.e. $K_{0}$ model, computation of $K_{0}$ from coordinate system origin to various engine stable states (Simple for various engine stable states).

For various stable states is gains $K_{i}$ or $K_{0}$ are different (various). For that reason, to achieve higher mathematical model accuracy, it is necessary to change gain $K$ depending on $Q_{p a l}$ change in real time. It may vary as in aircraft models by switch of models for various operating point, or as we propose for aircraft engines we will change them by gain approximation $K_{i, j}$, $\left(K_{0, j}\right)$ regarding the work of Pečinka and Jílek (2012).

In case of $K_{i}$ models, we will approximate gain $K_{i, j}$ by (3) for chosen operating point " $i$ " from fuel flow $Q_{p a l}$, i.e. for various $Q_{\text {pal }}$ we will obtain various $K_{i, j}$. That process we try as simple as possible (lowest polynomial degree) in first pilot approach only by polynomial function approximation. Polynomial function is sum or subtraction of monomial. It is equation in form:

$$
K_{i}^{Q p a l}\left(Q_{p a l}\right)=\sum_{i=0}^{n} a_{i} Q_{p a l}^{i}=a_{0}+a_{1} Q_{p a l}+a_{2} Q_{p a l}^{2}+\ldots+a_{n} Q_{p a l}^{n}
$$

where $a_{n} \neq 0$. Numbers $a_{0}, a_{1}, \ldots$, an are called polynomial coefficients. In our case we compute them for specific operating point " $i$ " as approximation (least square method) from computed $K_{i, j}$ by (3) for chosen operating point " $i$ " given to fuel flow $Q_{\text {pal }}$. Results are displayed below in other subtopics.

Besides that system gain is changed given to stable state, operating point in which engine is, (until now we discussed $K$ depending on $Q_{\text {pal }}$, in future it will be revolutions $\mathrm{n}$ ), gain even depends on altitude and airspeed of aircraft, which use engine as propulsion. By altitude and airspeed change is also changed input parameters into engine as atmospheric temperature, pressure or air humidity and more. $K$ is depending on following parameters:

$$
K=f\left(n, Q_{\text {pal }}, V, H, p_{0}, T_{0}, \text { humidity }, \ldots\right)
$$

In (6), $\mathrm{v}$ and $\mathrm{H}$ denote the velocity and altitude of flight, $\mathrm{p} 0$ and $\mathrm{T} 0$ those ambient pressure and temperature which arises at the operation. In our paper we focus only on change of $K$ depending on change of engine operating state. Both investigated engines are placed in the laboratories of the authors, in laboratory conditions, whereas temperature, pressure and other parameters we consider as constants.

\section{Nonlinear deviation model iSTC-21v 3.1 Deviation and non-deviation gain $\mathrm{K}$ process of engine iSTC-21v}

To compute deviation gain and create deviation model we need to choose operating point. Exactly by choosing operating point and impact to this choice given to resulting model accuracy we deal in this paper with three selected operating points, following:

- $Q_{p a l}=0.887 \mathrm{l} / \mathrm{min}, n=40908 \mathrm{rpm}$,

- $Q_{\text {pal }}=0.69 \mathrm{l} / \mathrm{min}, n=36000 \mathrm{rpm}$,

- $Q_{\text {pal }}=0.6993 \mathrm{l} / \mathrm{min}, n=36000 \mathrm{rpm}$.

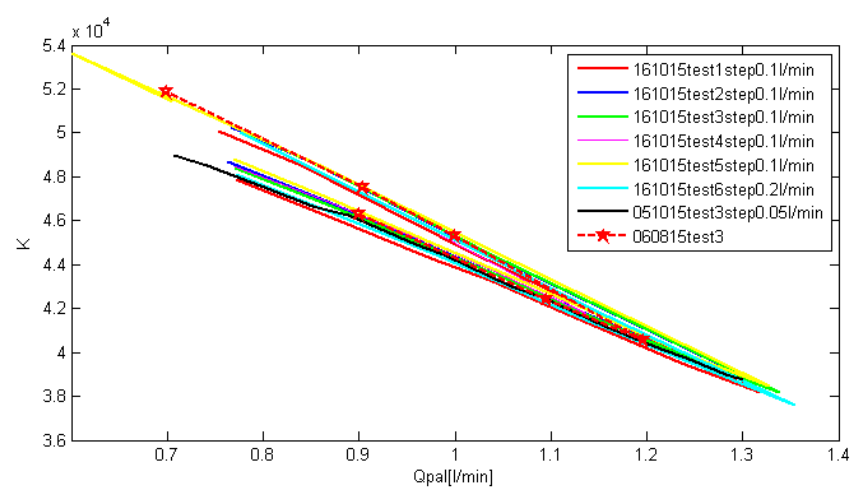

Fig. 2 Static gain $K$ dependence (non-deviation) from engine iSTC-21v revolutions for various input signals

\subsection{Approximation of deviation K depending on Qpal}

In this subtopic we will deal with approximation of $\Delta K=\mathrm{f}\left(Q_{p a l}\right)$ for selected operating points. All that dependencies we plotted in Fig. 3, where each area is gradually zoomed for better visibility. While range of $\Delta K$ values significantly changing exactly by impact of operating point selection. For approximation we used MATLAB software and its toolbox cftool, or directly polyfit and polyval function (see e.g. Horváth and Rudas (2013)). We tried to get polynomial function (see (5)) as simple as possible i.e. with lowest possible degree (simplicity in aeronautics).

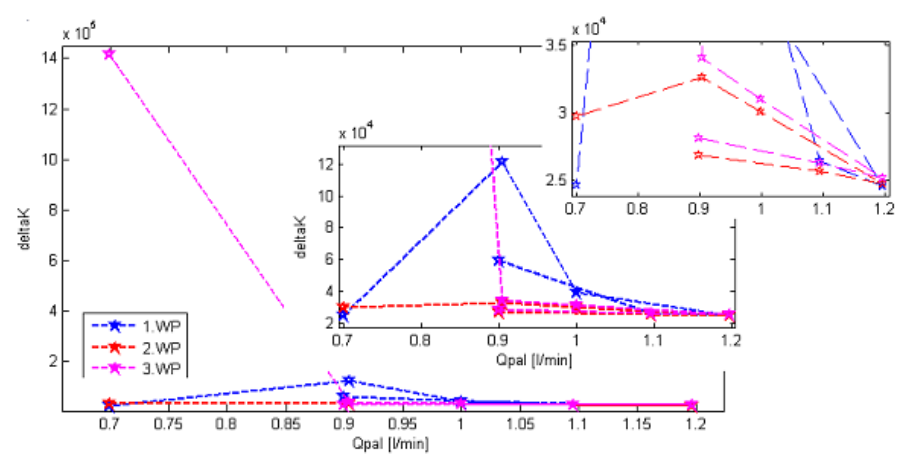

Fig. 3 Deviation $K$ depending on $Q_{p a l}$ for all 3 working points 
For first working point (1.WP) from value of deviation gain $\mathrm{K} 1, \mathrm{j}$ depending on fuel flow $Q_{\text {pal }}$, i.e. for dependence of $\Delta K_{1}=$ $\mathrm{f}\left(Q_{p a l}\right)$ marked on Fig. 4 as 1.WPorig, we made three different approximations (see Fig. 4).

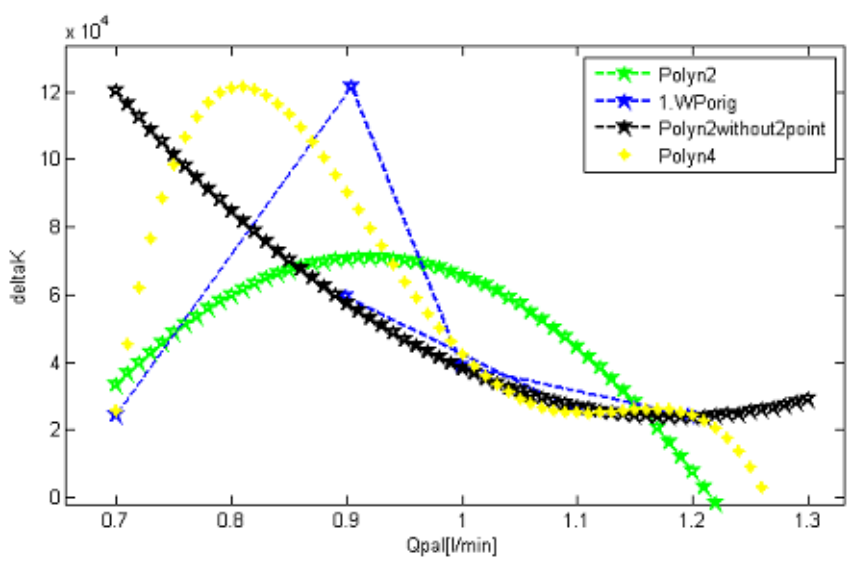

Fig. 4 Approximation of $\Delta K_{1}=\mathrm{f}\left(Q_{p a l}\right)$ by polynomial function of various degrees

On Fig. 5 all three $\Delta K_{\mathrm{i}}=\mathrm{f}\left(Q_{p a l}\right)$ approximation are displayed for the original working points (WPorig), i.e. 1.WPorig, 2.WPorig and 3.WPorig and their approximations, which in next will be investigated directly in deviation engine models. For 1.WPorig we will analyze three various approximations (1.WPolyn2without2point, 1.WPolyn2 and 1.WPolyn4), for 2.WPorig we selected and in following will work with approximation 2.WPolyn2 and for 3.WPorig we decided for approximation 3.WPower2 and in next we will compare results from engine revolutions model with real measured values in laboratory conditions LIRSLM.

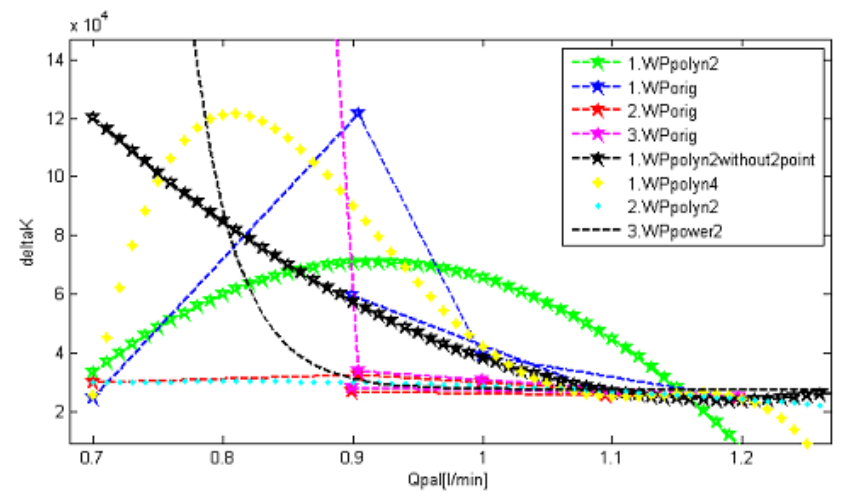

Fig. 5 All $\Delta K$ depending on $Q_{p a l}$ and their approximations

\subsection{Simulation of created and obtained nonlinear iSTC-21v models}

If we have created approximations for our obtained dependencies of $\Delta K_{\mathrm{i}}=\mathrm{f}\left(Q_{p a l}\right)$ and added into (1) we get nonlinear deviation engine models. In following it is necessary, as mentioned above, to perform an analysis of those models and their outputs to be compared with the measured engine revolutions in real time. For that reason was created simulation scheme (see Fig. 6) in MATLAB/Simulink.
That scheme in first part displays deviation linear engine model (gain $K$ is constant - it does not change) and in second part is deviation nonlinear engine model (gain $K$ is changing depending on $Q_{p a l}$ - with various computed approximations). Generally for deviation model is linear and nonlinear in simulation scheme we must subtract to input (in our case to $Q_{p a l}$ ) selected working point, for which we computed the deviation model, i.e. by (3) $u_{i}$, and on output add to output variable (in our case to $n$ ) value of revolutions corresponding for selected working point, i.e. $y_{i}{ }^{\prime}$. From that resulting simulation schemes will be same for all created and analyzed non-deviation nonlinear engine models, i.e. for various approximations according to working point, except of the polynomial function which approximates dependency $\Delta K_{\mathrm{i}}=\mathrm{f}\left(Q_{p a l}\right)$ and values $\left(u_{i, \infty}, y_{i{ }^{\prime} \infty}\right)$, which defines a working point.

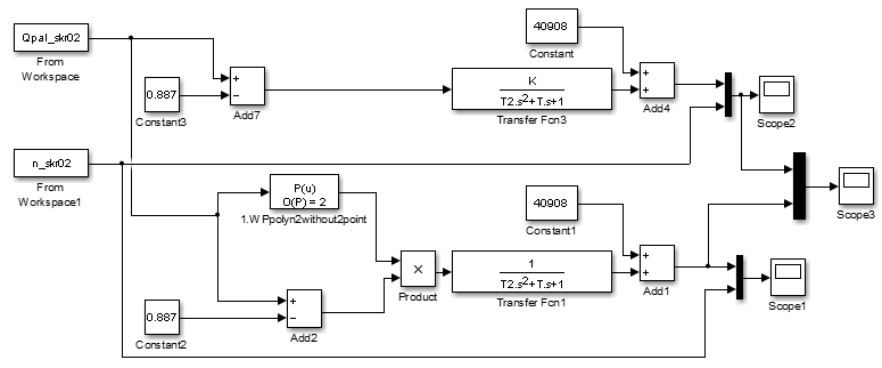

Fig. 6 Simulation scheme of deviation linear (above) and nonlinear (below) iSTC-21v model

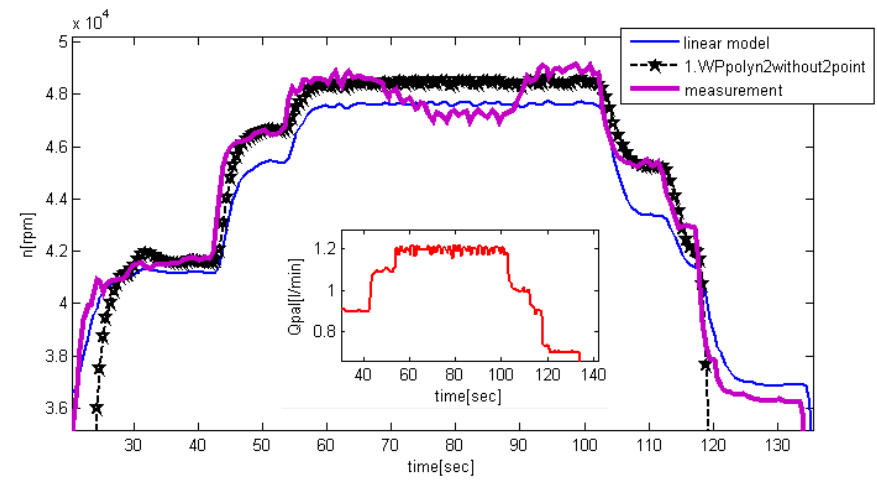

Fig. 7 Dependency of revolutions on time, clamped figure (smaller) dependency of Qpal on time

By successive simulating for chosen input signal we get output signals of revolutions in time for each obtained and created models and the real measured revolutions. These signals are displayed on following figures, in which measured values we will mark as measure and results from models by legend on Fig. 5 - marking of each approximations. Fig. 7 displays and compare measured revolutions with deviation model response of linear and nonlinear system (approximated 1.WPolyn2without2point) for fuel flow. On the smaller figure in the center the independent input value fuel flow into the engine is shown (input into model). At time 70sec. a change of output nozzle diameter was performed and for that reason also revolution 
decreased, while fuel flow was constant. Created models have not responded, what was due to the changing exhaust nozzle diameter, itemized in Főző et al. (2015) - it is not contained in this model yet. From Fig. 7 is clear that for lower engine thrust, i.e. for fuel flow $Q_{p a l}=0.7 \mathrm{l} / \mathrm{min}$, revolutions of the nonlinear model (1.WPolyn2without2point) leaving measured values and rapidly fall. Reason of that behavior is that approximation does not match original values in this region (see Fig. 5 1.WPolyn2without2point).

In following simulation scheme see Fig. 6 was extended for another nonlinear deviation models (more approximations and more working points, see Fig. 5). Except approximation as on Fig. 5 1.WPolyn2, which is omitted - model revolutions at all leaving measured values. Simulation results we can see on Fig. 8, while input signal $Q_{p a l}$ is same as on Fig. 7 clamped figure.

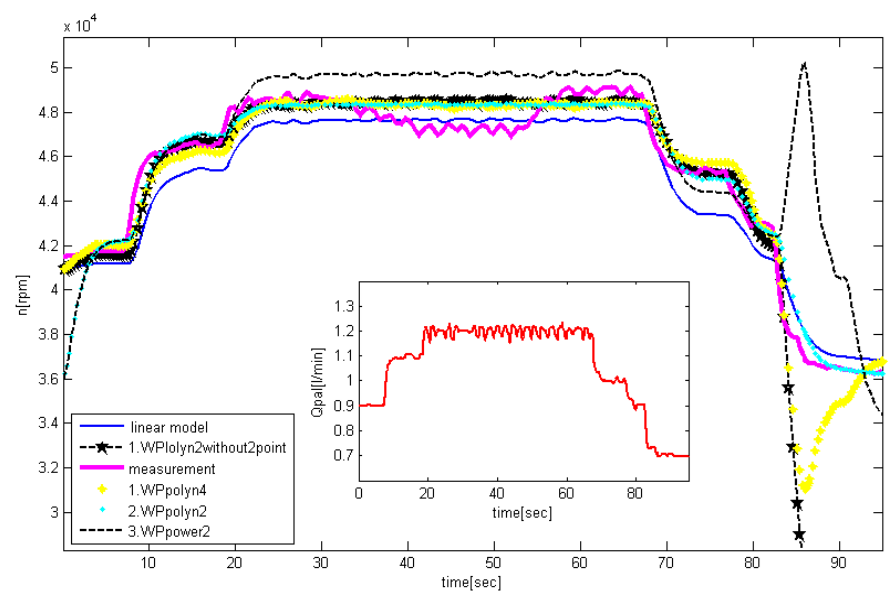

Fig. 8 Dependency in time, i.e. system response with other approximations of $\Delta K$ depending on $Q_{p a l}$, see Fig. 5

By statistical indicators MAE, MAPE, MAAE a MAAPE we compared obtained results from Fig. 8 (see Table 1). From obtained results in table and from Fig. 8 we can state the best results reaches linear model and from nonlinear models (approximations 1.WPolyn4 and 2.WPolyn2). On Fig. 8 one can see area input signal fuel flow $Q_{p a l}=0.9 \ldots 0.7 \mathrm{l} / \mathrm{min}$, where model response is different from real revolution value, it is caused by inaccuracies and approximations see Fig. 5.

Table 1 Evaluation to Fig. 8

\begin{tabular}{ccccc}
\hline & MAE [rpm] & MAPE [\%] & MAAE [rpm] & MAAPE [\%] \\
\hline linear & 916.7 & 2.06 & 3085.2 & 6.46 \\
1.WPolyn2 & 2694.2 & 7.1 & 18301 & 37.66 \\
1.WPolyn4 & 878.34 & 2.1 & 5903.9 & 12.16 \\
2.WPolyn2 & 921.62 & 2.13 & 5498.9 & 11.36 \\
3.WPower2 & 2141.8 & 5.18 & 13247 & 26.4 \\
\hline
\end{tabular}

To emphasize critical areas (lower engine modes - close to idle $Q_{\text {pal }}=0.9 \ldots 0.7 \mathrm{l} / \mathrm{min}$ and higher $\max$ modes up to $Q_{\text {pal }}=1.2 \mathrm{l} / \mathrm{min}$ ) of created models, we test them on different input signal (see Fig. 9).
To obtained plots displayed on Fig. 9 we computed statistical-quantitative indicators collected in Table 2, which confirmed success of linear model and approximation (2.Wpolyn2). On other side approximation and model marked as 1.WPolyn4 failed, critical areas are totally mishandled. Approximation Fig. 5 displays $\Delta K$ at higher modes rapidly fall.

It is important mention approximation 2.WPolyn2 do not follow max revolutions (at higher revolutions holds lower constant value), what is caused by approximation - polynomial function (see Fig. 5 zoom) falling for higher max modes, up to $Q_{\text {pal }}=1.2 \mathrm{l} / \mathrm{min}$, what is obviously not right. Linear model (nonlinear) is better in that way, even if it has deviations, only it get close to max modes. Results are slightly distorted, the linear model shows better results as approximation 2.WPolyn2 for example when computing MAPE, it is caused by left of statistical indicators and critical areas for clarity (big overshoots and undershoots), which in normal conditions are left or trimmed for computing.

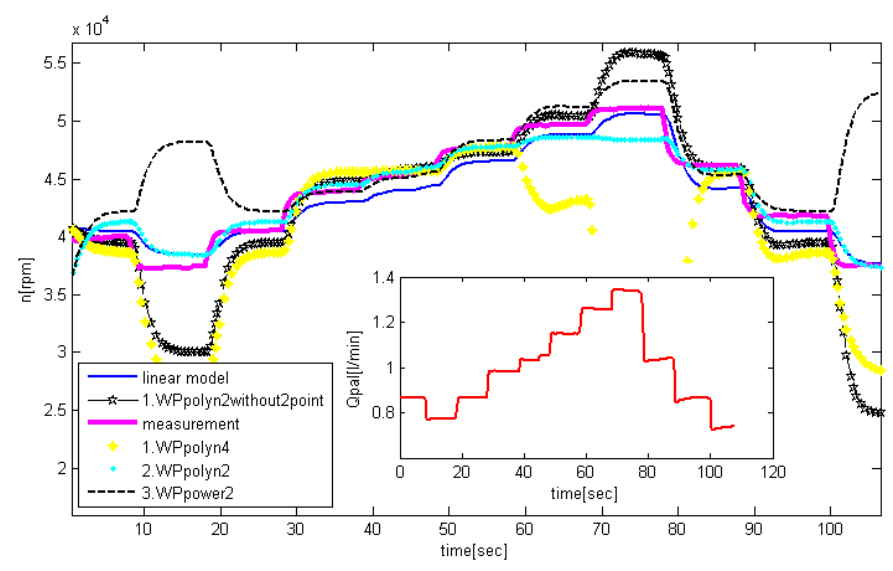

Fig. 9 Dependency in time, for various approximations from Fig. 5 and different input signal Qpal into the engine (red line)

Table 2 Evaluation to Fig. 9

\begin{tabular}{ccccc}
\hline & MAE [rpm] & MAPE [\%] & MAAE [rpm] & MAAPE [\%] \\
\hline linear & 1138.7 & 2.62 & 2621.2 & 5.18 \\
1.WPolyn2 & 2405.7 & 5.83 & 12634 & 22.59 \\
1.WPolyn4 & 7976.1 & 17.03 & 57251 & 119.8 \\
2.WPolyn2 & 1126.6 & 2.63 & 3678.2 & 7.56 \\
3.WPower2 & 2877 & 7.21 & 15016 & 28.07 \\
\hline
\end{tabular}

At the end we can state results from simulations, model output - how will revolutions follow real measured engine revolutions, will be very dependent from selected working point and approximations of $\Delta K_{i}=\mathrm{f}\left(Q_{p a l}\right)$. Of course we can aim on other approximation methods and their accuracy as on other variables on which gain $K$ depend (mainly on revolutions $n$ ), as showed by Lang and Kostrab (2015). In the conclusion of the present paper we highlight and compare with previously obtained results of nonlinear deviation engine model. Creation of that model is from 
time consuming side less difficult and working point selection lacks and also approximation of complex dependencies.

\section{Nonlinear non-deviation (absolute) iSTC-21v model}

In this topic we create pilot nonlinear non-deviation engine model, we approximate dependencies, or one specifically from Fig. 2 and simulate them compared to measured data. On Fig. 10 is displayed simulation scheme of deviation and non-deviation engine model. Non-deviation model is placed in subsystem and contain nonlinear non-deviation engine iSTC$21 \mathrm{v}$ mathematical model (assembled differential equation + approximation $K=\mathrm{f}\left(Q_{p a l}\right)$. Important change compared to deviation model in simulation scheme is lack of comparators (we do not subtract $u_{i}{ }^{\prime \infty}$ and do not add $y_{i},{ }_{\infty}$ ).

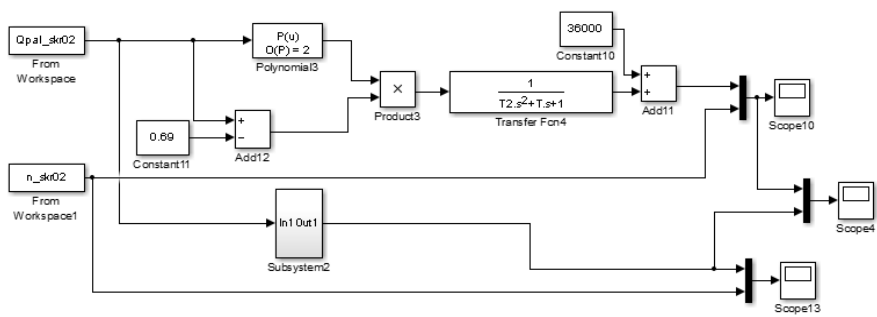

Fig. 10 Simulation scheme of iSTC-21v engine

Approximation $K_{0}=\mathrm{f}\left(Q_{\text {pal }}\right)$ for non-deviation nonlinear engine model was the simplest, i.e. polynomial function of first degree rectilinear dependence. From simulations obtained results are displayed on Fig. 11. From plots we can see that non-deviation nonlinear $K_{0}$ model follow also measured data at maximum revolution values and in other engine modes has same features as deviation nonlinear $K_{2}$ engine model (we chose just one best from obtained models above).

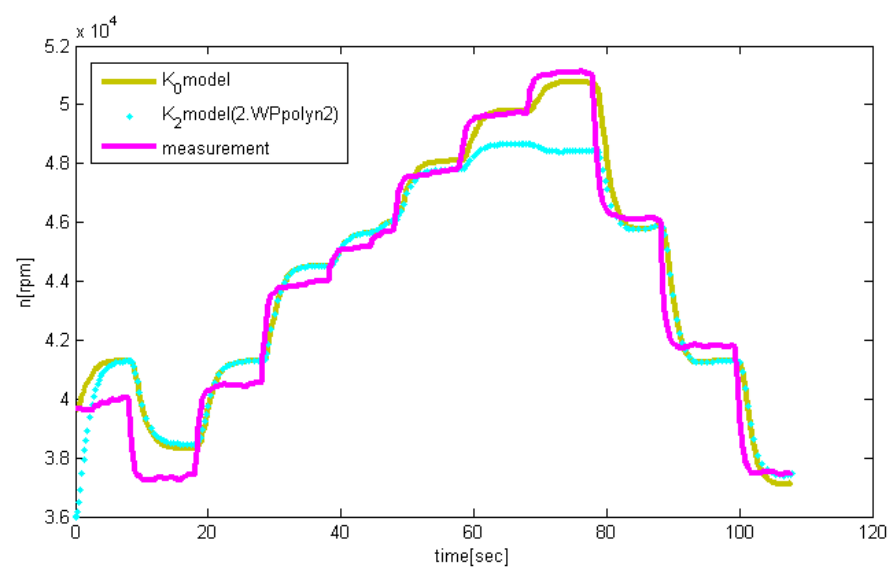

Fig. 11 Comparison of deviation and non-deviation iSTC-21v engine model

From obtained plots we computed statistical indicators see Table 3.
Table 3 Evaluation of Fig. 11

\begin{tabular}{ccccc}
\hline & $\begin{array}{c}\text { MAE } \\
{[\mathrm{rpm}]}\end{array}$ & $\begin{array}{c}\text { MAPE } \\
{[\%]}\end{array}$ & $\begin{array}{c}\text { MAAE } \\
{[\mathrm{rpm}]}\end{array}$ & $\begin{array}{c}\text { MAAPE } \\
{[\%]}\end{array}$ \\
\hline K0model & 730.26 & 1.75 & 3339.2 & 6.58 \\
K2mode12.WPolyn2 & 1126.6 & 2.63 & 3678.2 & 7.56 \\
\hline
\end{tabular}

Obtained results confirm accuracy and creation process of non-deviation model and model simplicity.

\section{Conclusions}

Basic question, witch which this paper deal is if our jet engine and similar systems i.e. which running above certain border (idle). Hocko and Polansky (2014) created mathematical models using experimental identification (in paper presented approximation of step responses, i.e. approximation of proportional system with inertia of first degree) it may be deviation or non-deviation, linear or nonlinear. If we create deviation models another question arises (problematic circle) how to select working point, from which deviation model is created. If we create deviation nonlinear model next question is how to approximate $\Delta K=\mathrm{f}\left(Q_{p a l}\right)$. Paper proves that for aircraft engines and similar systems have selection of working point big impact to model and approximation accuracy. And at the end of paper created non-deviation model with higher model accuracy arise into question if is necessary and if why, create deviation models. To future we need solve questions, how to model follow real revolutions in case if $K$ or also $\Delta K$ will be dependent on revolution, not on $Q_{p a l}$, what may be better from control algorithm side. If it is necessary to approximate time constant and its impact on computation (and together question) of deviation gain or non-deviation gain, more methods of experimental identification, for example successive integration method and more.

\section{Acknowledgement}

The work presented in this paper was supported by VEGA, Grant Agency of Ministry of Education and Academy of Science of Slovak Republic under Grant No.1/0776/17 - "Progressive algorithms in control, modeling and diagnostics of small jet engines". This paper is supported by KEGA under Grant No. 014TUKE-4/2015 - "Digitalization, virtualization and testing of a small turbojet engine and its elements using stands for modern applied lecturing". This support is very gratefully acknowledged.

\section{References}

Adamčík, F., Bréda, R., Kurdel, P., Beňo, V. (2014). Modeling of changes in flow air fuel effected by changes in environmental conditions. Naše More. 61(1-2), 2014. pp. 40-42.

Andoga, R., Madarász, L., Fozo, L., Lazar, T., Gašpar, V. (2013). Innovative approaches in modeling, control and diagnostics of small turbojet engines. Acta Polytechnica Hungarica. 10(5), pp. 81-99. https://doi.org/10.12700/APH.10.05.2013.5.6 
Armstrong, J. B., Simon, D. L. (2012). Implementation of an Integrated Aircraft Engine Diagnostic Architecture. NASA/TM-2012-217279, AIAA-2011-5859, 2012.

Beneda, K. (2015). Development of a Modular FADEC for Small Scale Turbojet Engine. In: Proceedings of SAMI 2016 - IEEE $14^{\text {th }}$ International Symposium on Applied Machine Intelligence and Informatics, Herl'any, Jan. 21-23, 2016. pp. 51-56. https://doi.org/10.1109/SAMI.2016.7422981

Bicsák, Gy., Veress Á. (2015). Verification of a CostEfficient Solution to Simulate the Airflow Conditions in an Oil-To-Air Heat Exchanger of a Small Aircraft Applying Porous Material. In: Repüléstudományi Közlemények. (Aeronautical Scientific Publications.) 27(2), pp. 253-271. URL: http:// www.repulestudomany.hu/folyoirat/2015_2/2015-2-19-0209_Bicsak_ Gyorgy-Veress_Arpad.pdf

Főző, L., Andoga, R., Madarász, L., Kolesár, J., Judičák, J. (2015). Description of an intelligent small turbo-compressor engine with variable exhaust nozzle. In: SAMI 2015 - IEEE $13^{\text {th }}$ International Symposium on Applied Machine Intelligence and Informatics, Herl'any, Jan. 22-24, 2015, pp. 157-160. https://doi.org/10.1109/SAMI.2015.7061867

Hocko, M., Polansky, J. (2014). Transformation of an aviation turboshaft engine into a experimental jet engine for laboratory testing unstable radial compressor work. In: Proceedings of ASME International Mechanical Engineering Congress and Exposition (IMECE), Volume 5: Education and Globalization. Montreal, Canada, Nov. 14-20, 2014. https://doi.org/10.1115/IMECE2014-37298

Horváth, L., Rudas, I. J. (2013). Active knowledge for the situation-driven control of product definition. Acta Polytechnica Hungarica. 10(2), pp. 217-234. https://doi.org/10.12700/APH.10.02.2013.2.15

Jaw C. L., Mattingly D. J. (2009). Aircraft Engine Controls Design, System Analysis, and Health Monitoring. American Institute of Aeronautics and Astronautics.

Jirgl, M., Jalovecky, R. (2015) Parameters identification of the dynamic models of pilot behavior. In: Transport Means - Proceedings of the International Conference, Jun. 2015, pp. 368-371.
Kulikov, G. G., Thompson, H. A. (2004). Dynamic Modeling of Gas Turbines Identification, Simulation, Condition Monitoring and Optimal Control, Springer 2004.

Lang, J., Kostrab, R. (2015). Event based application of voting system for mobile device. In: Proceedings of SAMI 2015 - IEEE $13^{\text {th }}$ International Symposium on Applied Machine Intelligence and Informatics, Herl'any, Jan. 22-24, 2015, pp. 119-122. https://doi.org/10.1109/SAMI.2015.7061859

Noskievic P. (1999). Modelovánía a identifikace systemů. (Modelling and system identification). Ostrava, Montanex. (in Czech)

Pečinka, J., Jílek, A. (2012). Preliminary Design of a low-cost Mobile Test Cell for Small Gas Turbine Engines (GT2012-69419) In: Proceedings of ASME Turbo Expo 2012. Copenhagen: ASME, 2012. https://doi.org/10.1115/GT2012-69419

Rohács, D., Rohács, J. (2016). Magnetic levitation assisted aircraft take-off and landing (feasibility study - GABRIEL concept). Progress in Aerospace Sciences. 85, pp. 33-50. https://doi.org/10.1016/j.paerosci.2016.06.001

Tóth-Laufer, E., Takács, M., Rudas, I. J. (2015). Fuzzy logic-based risk assessment framework to evaluate physiological parameters. Acta Polytechnica Hungarica. 12(2), pp. 159-178. https://doi.org/10.12700/APH.12.2.2015.2.10

Truman, T., de Graaff, A. $(2006,2007)$ Out of the box, Ideas about the future of air transport, Part 1, ASTERA/ ACARE, Koninklijke de Swart, Den Haag, 2006, p. 108. Part 2, EC Directorate-General for Research, ACARE, Brussels, 2007. p. 91.

Zare, F., Veress, Á. (2013). Mathematical Model Development and Thermodynamical Cycle Analyses of a Dual Spool no By-pass and a Dual Spool Mixed Turbofan Engines. In: International Conference on Innovative Technologies (IN-TECH) 2013. Budapest, Hungary. 2013. pp. 41-44. URL: http://www.in-tech.info/download/intech_proceedings_2013.pdf 